\title{
Severe facial dermatitis as a late complication of aesthetic rhinoplasty; a case report
} Mohammad Hossain Rajabian ${ }^{1}$, Manoochehr Sodaify² and Shahin Aghaei*2

Address: ${ }^{1}$ Department of Plastic Surgery Shiraz University of Medical Sciences, Shiraz, Iran and ${ }^{2}$ Department of Dermatology Shiraz University of Medical Sciences, Shiraz, Iran

Email: Mohammad Hossain Rajabian - rajabim@sums.ac.ir; Manoochehr Sodaify - sodaifym@sums.ac.ir; Shahin Aghaei* - shahinaghaei@yahoo.com

* Corresponding author

Published: 31 March 2004

BMC Dermatology 2004, 4:1
Received: 28 October 2003

Accepted: 31 March 2004

This article is available from: http://www.biomedcentral.com/I47/-5945/4/I

(C) 2004 Rajabian et al; licensee BioMed Central Ltd. This is an Open Access article: verbatim copying and redistribution of this article are permitted in all media for any purpose, provided this notice is preserved along with the article's original URL.

\begin{abstract}
Background: Contact dermatitis, as a cutaneous complication after rhinoplasty, is of early onset, limited and transient. The cause of this dermatitis is irritant or allergic. Late onset skin complications are rare and non-inflammatory.
\end{abstract}

Case presentation: We are reporting an unexpected, severe allergic contact dermatitis of the face, in a young female, appearing one month following aesthetic rhinoplasty. She failed to respond to ordinary treatments for dermatitis. We did standard battery - including nitrofurazone, tincture of benzoin and hydrocortisone - patch test for the patient that showed sensitivity to benzoin and corticosteroid.

Conclusions: In summary we report a case of a severe allergic contact dermatitis of the face, in a 2I-year-old girl who underwent corrective aesthetic rhinoplasty, appearing one month following surgical operation. We were unable to find a similar report in the medical literature.

\section{Background}

Cutaneous problems after rhinoplasty are usually early, minor, and transient [1]. Most common being contact dermatitis, appearing as rashes or pustules with or without allergic reactions from the tape which might have been used with tincture of benzoin or a preparation containing gum mastic $[2,3]$. These substances are frequently used as a dressing support and to increase adhesive strength of the tape. The tape can cause necrosis, a major complication, if applied too tightly $[1,4]$. Patients with acne might find their condition temporarily worse just after rhinoplasty as a result of the local effect of the dressing or the systemic response to the operation [4].

Late cutaneous complications are limited to permanent redness and telangiectasias of the nasal skin in some patients with a diathesis toward capillary telangiectasias $[1,4]$.

We report a severe dermatitis of the nose and adjacent skin areas starting one month after aesthetic rhinoplasty in an otherwise healthy young girl.

\section{Case presentation}

A 21-year-old girl underwent corrective aesthetic rhinoplasty by endo-nasal technique in September 2000. She was healthy with an apparently normal skin and no evidence of acne was seen (figure 1). Facial preparation was made by povidone iodine scrub. Neither autologus or heterologus tissues nor foreign materials were used as a transplant. Chromic catgut, vicryl and nylon (all from Ethicon CO.) were used as suture materials. Nasal vestibules were 


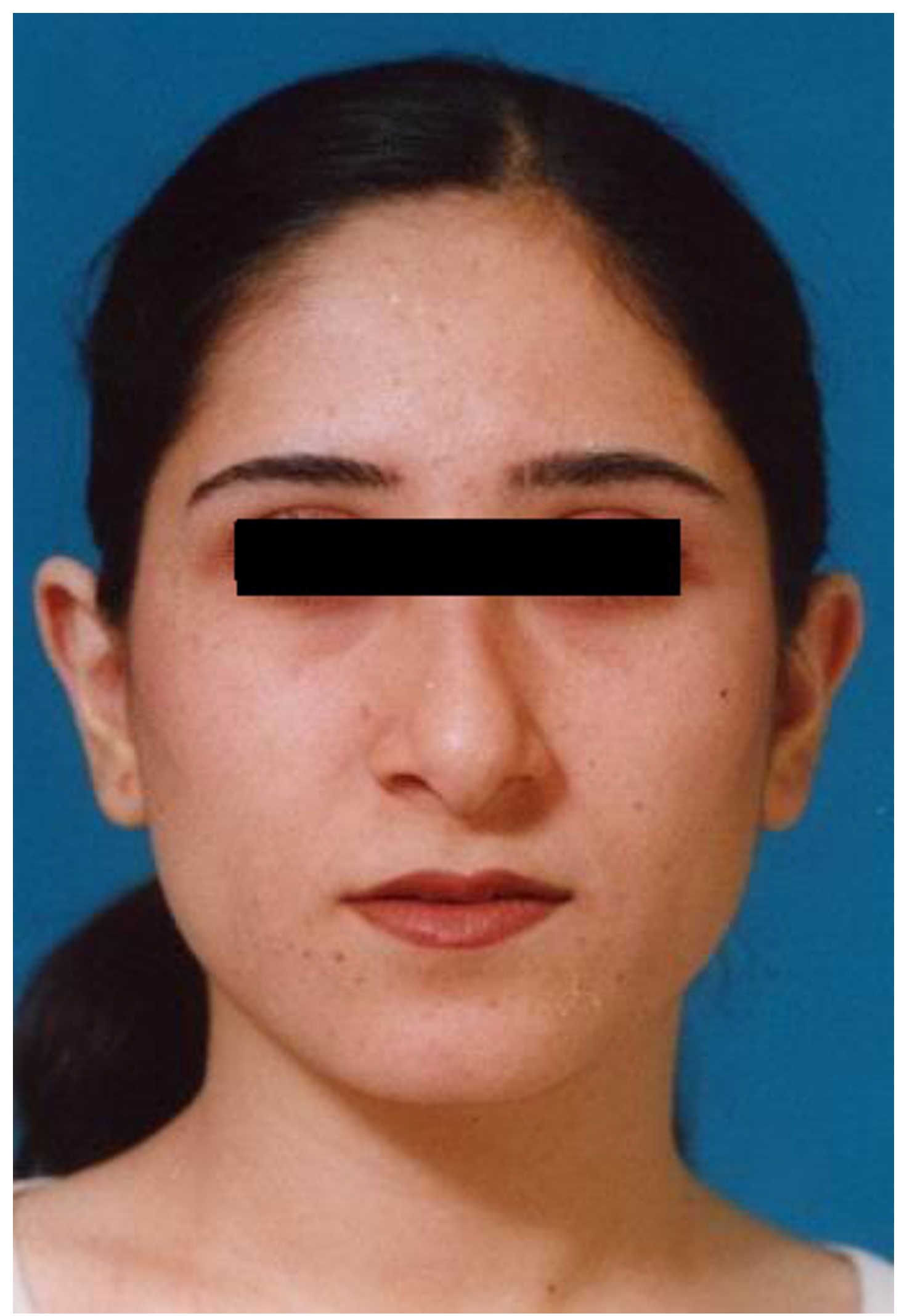

Figure I

Preoperative view of the patient.

Page 2 of 7 


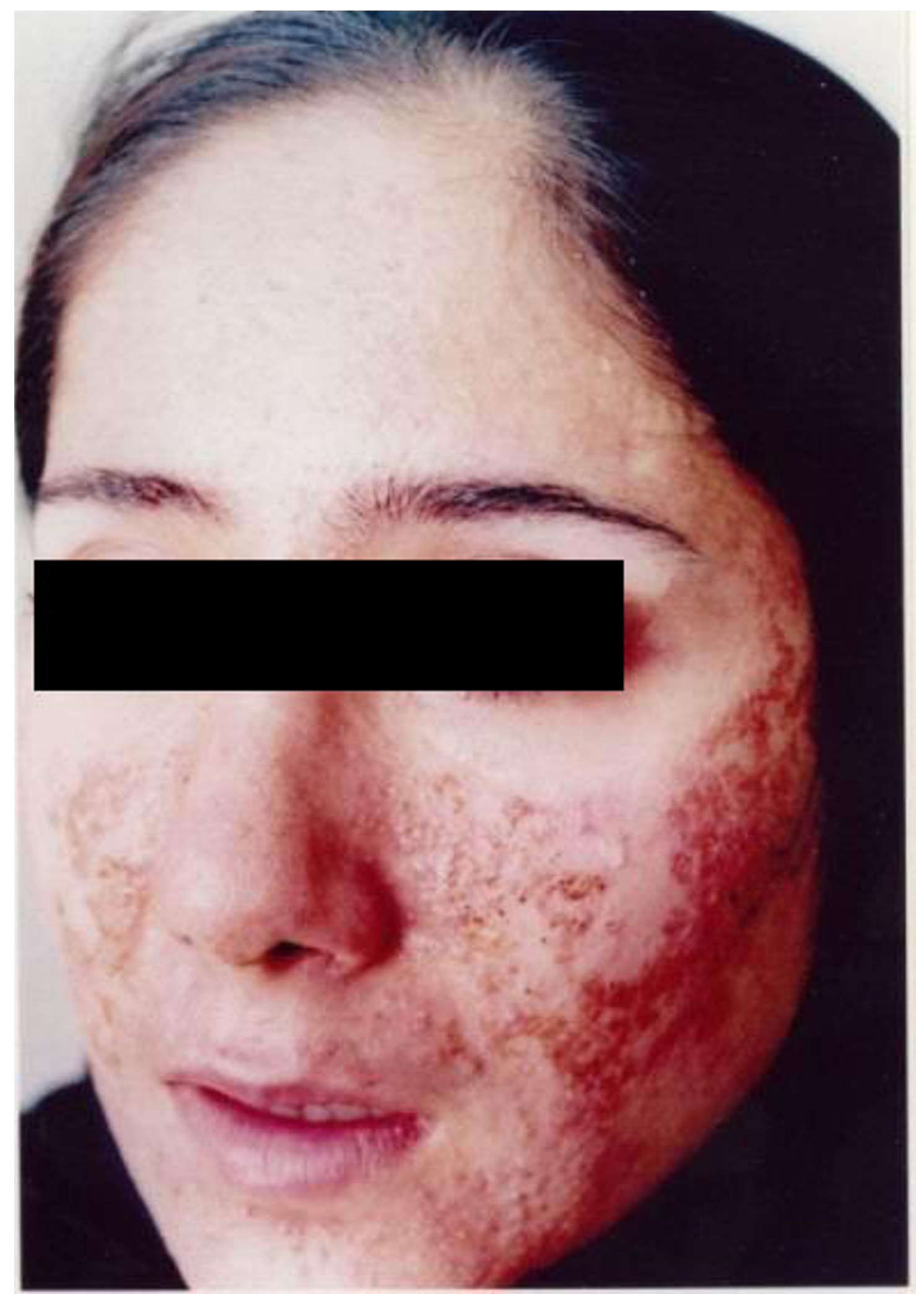

Figure 2

Photograph of the patient 3 months after operation. Note generalized eruptions with severe erythema, weeping, and crusted vesicles. 
packed with petrolatum meshes impregnated with nitrofurazone ointment. The nose, glabellar region, and cheeks painted with tincture of benzoin. The $3 \mathrm{M}$ hypo allergic tapes applied over the nose under the plaster cast and over the cast extending to both cheeks and forehead in order to fix it in place. She received prophylactic cephalexin 500 mg q 6 h, for 3 days and acetaminophen with codeine 325 mg q8 h, for a couple of days. Recovery was uneventful. Cast and tapes were removed nine days post surgery. She was satisfied with the aesthetic result. Facial skin was normal. The same type of tapes, without tincture of benzoin, reapplied over the nose for another 5 days to control the edema. She did quite well till one month after cast removal. During this period, she did not use any topical agents on the face or come in contact with anything such as swimming goggles. Then she began to notice small red papules and vesicles over the nose, cheeks and forehead, being covered by yellowish-brown crusts in some parts. Lesions gradually got severe and more exudative, extending to whole mid face and then rest of the face within three months (figure 2).

She had no itching and was afebrile. No history of severe allergy (including rubber products), urticaria, asthma, or herpes simplex could be found in the patient or her close relatives. She had positive history of mild acne prior to surgery. As she failed to respond to ordinary treatments for dermatitis, like potassium permanganate in 1:5000 dilution plus low dose systemic steroids (prednisolone, $10 \mathrm{mg}$ PO, q24 h for 10 days), we did standard battery patch test (European standard) for her - that we add nitrofurazone, tincture of benzoin and hydrocortisone to the test - which the test showed sensitivity to benzoin and topical corticosteroid (patch test grading was 1+ in each agent). Laboratory examinations including, $\mathrm{KOH}$ preparation, Gram stain and fungal and bacterial culture, were negative. We advised frequent and vigorous scrubbing of the face by povidone iodine soap which showed considerable improvement within 6 weeks (figure 3). Resolution of lesions was gradual and was almost fully completed at 8 months after surgery. On follow-up, she has shown no evidence of recurrence up to now (December 2002) (figure 4).

\section{Discussion}

Late onset skin problems following corrective rhinoplasty are rare and limited to non-inflammatory conditions such as permanent redness and telangiectasias of the nasal skin $[1,4]$. These small spider lesions do not transgress from the nasal skin and usually are seen in patients with a diathesis toward capillary telangiectasias. Inclusion mucoid cyst is another late non-inflammatory complication of rhinoplasty [4-6].
Acute contact dermatitis as a complication of rhinoplasty may have an irritant or allergic causation.

Irritant contact dermatitis is the most common contactrelated dermatosis. The injury to the skin may be mild, with only erythema, or severe with tissue necrosis and bulla formation. The patient may note a stinging or burning sensation with the onset of blisters or erythematous plaques which may spread from the area of contact to adjacent skin [2,7].

Allergic contact dermatitis is a delayed cell-mediated immunologic reaction to an exogenous allergen. It usually occurs between 24 and 48 hours after contact, but may be delayed up to 14 days. The eruption tends to be associated with moderate to severe erythema and pruritus with acute weeping and crusted vesicles. Diagnosis of allergic contact dermatitis may be confirmed by patch testing [2,7]. In a recent study, 45 out of 477 patients had a positive reaction to compound tincture of benzoin, which was the third most common allergen in their series. Of these 45 patients, 14 had strong positive reactions, but only two definitely recalled exposure to compound tincture of benzoin, and these were clinically revealed [3].

The treatment for acute contact dermatitis, whether allergic or irritant includes removal of the source, expression of pustules, irrigation with a drying desquamating soap and use of topical and systemic steroids as well as systemic antihistamines $[1,2,7]$.

The patient reported herein represents an interesting, unexpectedly late occurrence of acute contact dermatitis following rhinoplasty. One month after surgery, when every thing was over and she was supposed to refer to the clinic for follow up, she started to show symptoms of dermatitis. This timing of onset of symptoms suggests an allergic phenomenon. She gave no history of any episode of dermatitis, either irritant or contact type to happen previously. Interestingly patch testing was positive only for benzoin and steroids. Therefore, she did not respond to neither topical nor systemic steroid. Also, she had received antibiotic agents. This patient probably had allergic contact dermatitis (from tincture of benzoin or topical steroid), except for the fact that she did not have pruritus associated with the rash.

When everything was discontinued, gradually dermatitis settled down. Of course, frequent and vigorous massaging with tap water and plain soap has accelerated her improvement. There is a single report of refractory facial cellulitis following cosmetic rhinoplasty after cord-blood stem cell transplantation [8]. 


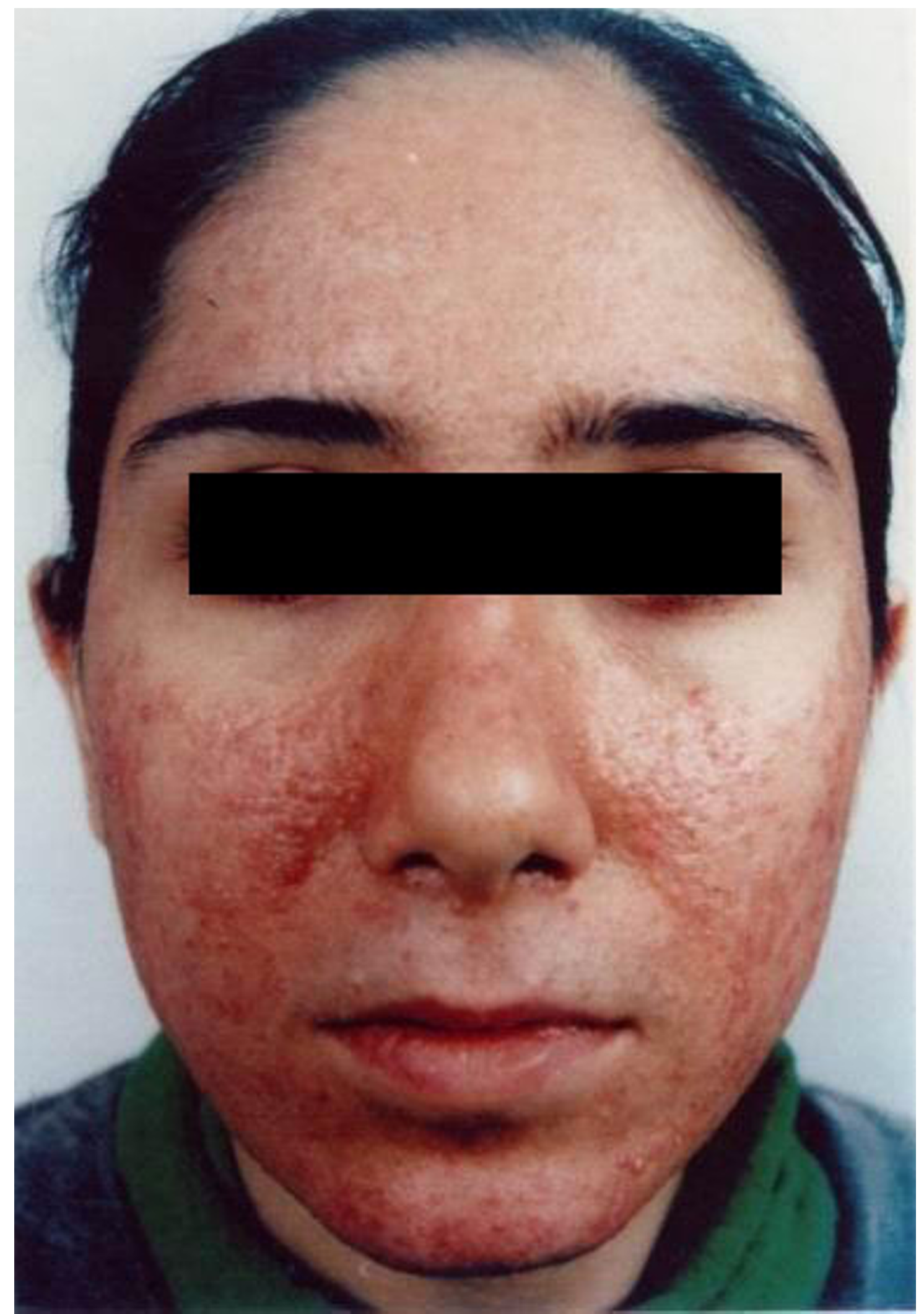

Figure 3

Relative improvement of dermatitis 4.5 months post surgery. 


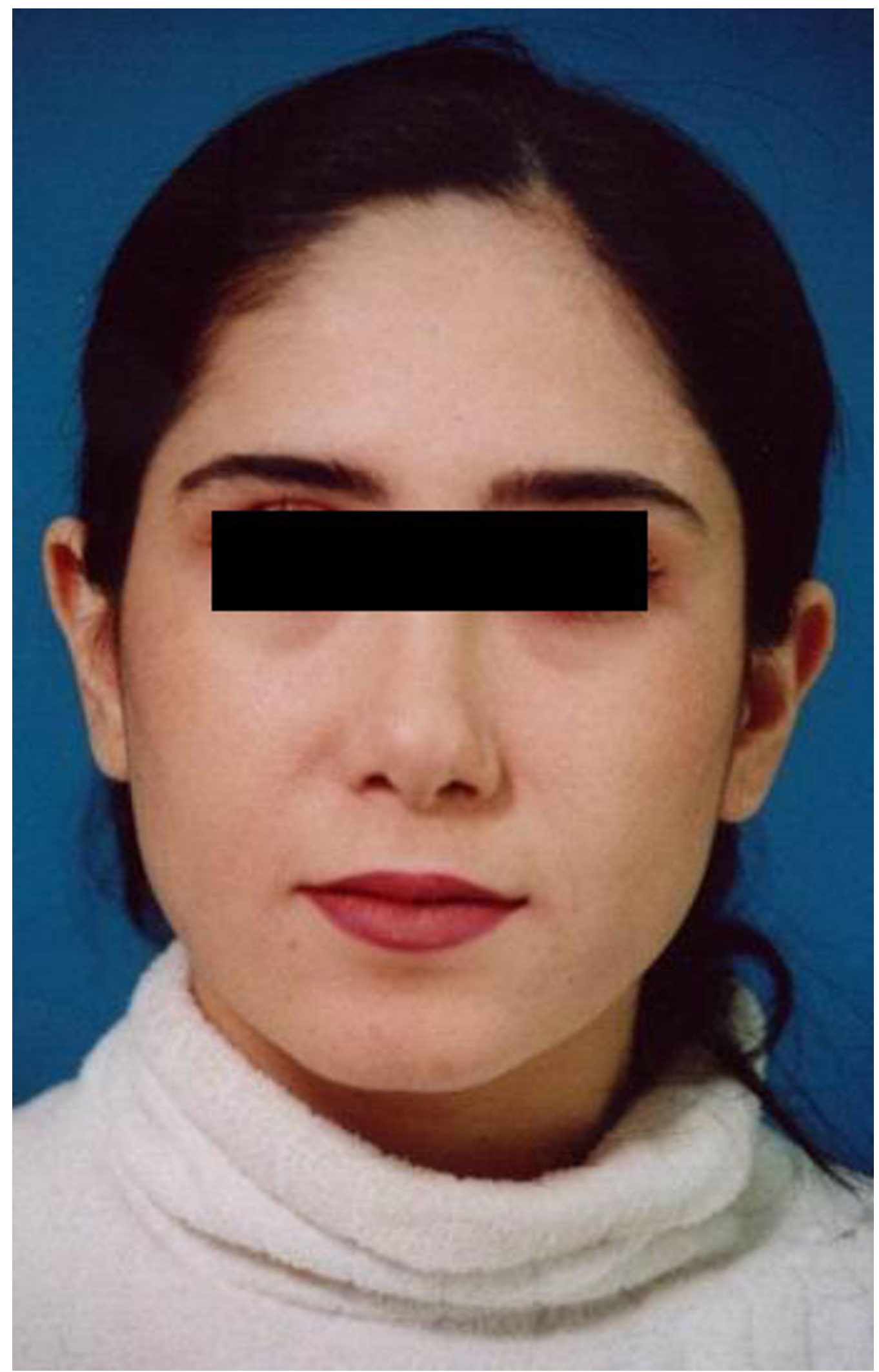

Figure 4

Photograph of the patient 2 years later. 


\section{Acknowledgement}

Written consent was obtained from the patient for publication of her details and figures. The authors thank the patient for this consent.

\section{References}

I. Rees TD: Postoperative considerations and complications. In Aesthetic plastic Surgery 2nd edition. Edited by: Rees TD, LaTrenta GS. Philadelphia: W.B. Saunders; 1994:335-400.

2. Mabrie DC, Papel ID: An unexpected occurrence of acute contact dermatitis during rhinoplasty. Archives of Facial Plastic Surgery I999, I:320-21.

3. Scardamalgia L, Nixon R, Fewing J: Compound tincture of benzoin: a common contact allergen? Australas J Dermatol 2003, 44(3): $180-4$.

4. Gruber RP, Aiach G: Open rhinoplasty. In The Unfavorable Result in Plastic Surgery, Avoidance and Treatment 3rd edition. Edited by: Goldwyn RM, Cohen MN. Philadelphia: Lippincott, Williams \& Wilkins; 2001:950-8I.

5. Senechal G, Senechal B, Mamelle G: A rare and late complication of rhinoplasties. Ann Otolaryngol Chir Cervicofac 198I, 98:385-6.

6. Mouly R: The mucoid cyst, unusual complications of rhinoplasty. Ann Chir Plast 1970, 15:153-5.

7. Martini MC: Contact dermatitis and contact urticaria. In Principles and Practice of Dermatology Edited by: Sams WM. New York, NY: Churchill Livingstone Inc; 1990:389-40I.

8. Machida U, Tojo A, Ooi J et al.: Refractory facial cellulitis following cosmetic rhinoplasty after cord-blood stem cell transplantation. Int J Hematol 2000, 72:98-100.

\section{Pre-publication history}

The pre-publication history for this paper can be accessed here:

http://www.biomedcentral.com/1471-5945/4/1/prepub

Publish with Bio Med Central and every scientist can read your work free of charge

"BioMed Central will be the most significant development for disseminating the results of biomedical research in our lifetime. "

Sir Paul Nurse, Cancer Research UK

Your research papers will be:

- available free of charge to the entire biomedical community

- peer reviewed and published immediately upon acceptance

- cited in PubMed and archived on PubMed Central

- yours - you keep the copyright

Submit your manuscript here:

http://www.biomedcentral.com/info/publishing_adv.asp 